\title{
AÇÕES DE EDUCAÇÃO PATRIMONIAL NO EXTREMO SUL CATARINENSE INCENTIVANDO A ESCOLA A PRESERVAR O PATRIMÔNIO ARQUEOLÓGICO
}

\author{
Juliano Bitencourt Campos ${ }^{1}$ \\ Marcos César Pereira Santos ${ }^{2}$ \\ Jairo José Zocche ${ }^{3}$ \\ Diego Dias Pavei ${ }^{4}$ \\ Hérom Silva de Cezaro ${ }^{5}$ \\ André Luiz Martins Ribeiro ${ }^{6}$ \\ Lauro Carrer ${ }^{7}$ \\ Lucy Cristina Ostetto ${ }^{8}$
}

\section{RESUMO}

Este artigo socializa os resultados do projeto de extensão aprovado pelo edital n. 32016 da Universidade do Extremo Sul Catarinense (UNESC), intitulado "Arqueologia Pública no Extremo Sul Catarinense: incentivando os pequenos a valorizar e preservar o patrimônio". O projeto foi desenvolvido em parceria com o Museu de Arqueologia e a Secretaria de Educação em turmas de Ensino Fundamental I da Escola Municipal José Réus, localizada no município de Balneário Rincão, sul de Santa Catarina. Buscou-se, por meio da Educação Patrimonial, envolver professores e alunos para conscientizá-los da importância da preservação dos sítios arqueológicos localizados no município, os quais se colocam como um patrimônio a ser valorizado e preservado pela comunidade. A metodologia utilizada incluiu oficinas, palestras e saída de campo com foco na cultura material pré-histórica e histórica da região, a função do arqueólogo e as atividades desenvolvidas no Laboratório de Arqueologia Pedro Ignácio Schmitz (LAPIS/UNESC). Foi salientado o papel do museu arqueológico do município na preservação do patrimônio local. Reiteramos que projetos como este contribuem para que o patrimônio local continue sendo reconhecido a partir do

\footnotetext{
${ }^{1}$ Professor do Programa de Pós-Graduação em Ciências Ambientais (PPGCA) e coordenador do Laboratório de Arqueologia Pedro Ignácio Schmitz (LAPIS) Universidade do Extremo Sul Catarinense (UNESC). E-mail: jbi@unesc.net.

2 Doutor em Arqueologia pela Università degli Studi di FerraraUNIFE. Muséum national d'Histoire naturelleMNHN International Doctorate in Quaternary and Prehistory (IDQP). Ferrara FE, Itália. Pesquisador do Laboratório de Arqueologia Pedro Ignácio Schmitz (LAPIS) Universidade do Extremo Sul Catarinense (UNESC).

${ }^{3}$ Professor do Programa de Pós-Graduação em Ciências Ambientais (PPGCA) e coordenador do Laboratório de Ecologia de Paisagem e de Vertebrados (LABECO) Universidade do Extremo Sul Catarinense (UNESC).

${ }^{4}$ Mestrando do Programa de Pós-Graduação em Antropologia da Universidade Federal de Pelotas (UFPEL). Pesquisador do Laboratório de Arqueologia Pedro Ignácio Schmitz (LAPIS) Universidade do Extremo Sul Catarinense (UNESC).

${ }^{5}$ Mestre em História pela Universidade do Vale do Rio dos Sinos (UNISINOS). Atua no setor de Arqueologia na Universidade do Extremo Sul Catarinense (UNESC).

${ }^{6}$ Bolsista do Projeto de Extensão edital n. 32016 UNESC. Graduando em História - Licenciatura na Universidade do Extremo Sul Catarinense (UNESC).

${ }^{7}$ Bolsista do Projeto de Extensão edital n. 32016 UNESC. Graduando em História - Licenciatura na Universidade do Extremo Sul Catarinense (UNESC).

${ }^{8}$ Doutoranda em História pela Universidade Federal de Santa Catarina (UFSC). Professora dos Departamentos de Pedagogia e História na Universidade do Extremo Sul Catarinense (UNESC).
}

\begin{tabular}{|l|l|l|l|l|l|l|l} 
(C) Rev. Arqueologia Pública & Campinas, SP & v.12 & n.1 & p. & Jul/2018 & ISSN 2237-8294
\end{tabular}


momento que dialoga com a comunidade, colocando-a como parceira neste processo de preservação e salvaguarda.

PALAVRAS-CHAVE: pré-história, História, Educação Patrimonial, Arqueologia, sambaqui.

\section{ABSTRACT}

This article socializes the results of the extension project approved by edital n. 32016 of the Universidade do Extremo Sul Catarinense (UNESC), entitled "Public Archeology in the South of Santa Catarina State: encouraging the small ones to value and preserve the heritage". The project was developed in partnership with the archeology museum and the Secretariat of Education in elementary school classes of the José Réus municipal school, located in the municipality of Balneário Rincão, south of Santa Catarina. Through Heritage Education, it was intended to involve teachers and students to raise awareness of the importance of preserving the archaeological sites located in the municipality, which are presented as a heritage to be valued and preserved by the community. The methodology used included workshops, lectures and field trips focusing on the prehistoric and historical material culture of the region, the role of the archaeologist and the activities developed at the Archeology Laboratory Pedro Ignácio Schmitz (LAPIS / UNESC). It was emphasized the role of the archaeological museum of the municipality in the preservation of the local patrimony. We reiterate that projects like this one contribute to the local patrimony being recognized as soon as it dialogues with the community, placing it as a partner in this process of preservation and safeguarding.

KEYWORDS: prehistory, History, Patrimonial Education, Archeology, sambaqui.

\section{INTRODUÇÃO}

Pensar a história, a cultura, o patrimônio e a ciência junto às comunidades do Extremo Sul Catarinense tem sido um dos objetivos de pesquisa do projeto "Arqueologia entre Rios: do Urussanga ao Mampituba", que além de realizar ações relacionadas à gestão integrada do território desde 2012 (CAMPOS et al. 2015; CAMPOS et al. 2013b), foca seus estudos arqueológicos na Préhistória Regional (CAMPOS et al., 2013a; CEZARO, SANTOS, CAMPOS, 2016; SANTOS, COSTA, CAMPOS, 2015; SANTOS, PAVEI, CAMPOS, 2016, 2018). Esses diferentes enfoques de pesquisa são desenvolvidos pelo Laboratório de Arqueologia Pedro Ignácio Schmitz (LAPIS) da Universidade do Extremo Sul Catarinense (UNESC), contribuindo com o estudo e a socialização do conhecimento arqueológico junto às comunidades escolares por meio da Educação Patrimonial.

Nessa perspectiva, o projeto de extensão intitulado "Arqueologia Pública no Extremo Sul Catarinense: incentivando os pequenos a valorizar e preservar o patrimônio" foi aprovado e posteriormente executado no prazo de 2 anos. As ações foram desenvolvidas em parceria com o Museu de Arqueologia e a Secretaria de Educação do município de Balneário Rincão, sul de Santa Catarina. Este projeto teve como objetivo contribuir com a valorização e preservação do patrimônio arqueológico local por meio de oficinas, palestras e aulas de campo, tendo como interlocutores estudantes das turmas de Ensino Fundamental I da Escola Municipal José Réus. As atividades buscaram incentivar e envolver os estudantes no processo de reconhecimento e valorização do patrimônio arqueológico, pois compreendemos que a 
[...] A Educação Patrimonial constitui-se de todos os processos educativos formais e não formais que têm como foco o Patrimônio Cultural, apropriado socialmente como recurso para a compreensão sócio-histórica das referências culturais em todas as suas manifestações, a fim de colaborar para seu reconhecimento, sua valorização e preservação. Considera ainda que os processos educativos devem primar pela construção coletiva e democrática do conhecimento, por meio do diálogo permanente entre os agentes culturais e sociais e pela participação efetiva das comunidades detentoras e produtoras das referências culturais, onde convivem diversas noções de Patrimônio Cultural. (IPHAN, 2014, p. 19).

\section{A IMPORTÂNCIA EM INCENTIVAR AS CRIANÇAS A PRESERVAREM O PATRIMÔNIO}

Educação Patrimonial, principalmente direcionada às crianças, deve ser um instrumento de educação no processo do ensino formal e não formal, bem como um instrumento de "alfabetização cultural", aqui entendido como uma "pedagogia que propõe a descolonização da memória e do imaginário do ser humano através do diálogo cultural com outros atores, por meio de processos de sensibilização, autoleitura, autoconscientização e transformação coletiva" (BARON, 2004, p. 419). Portanto, através da alfabetização cultural o projeto buscou rever, transformar e aprimorar formas de integrar e conhecer o patrimônio arqueológico de Balneário Rincão junto às escolas da rede pública de ensino, contribuindo para que a comunidade escolar se aproxime desses saberes e culturas, e possa, assim, transformar-se em agentes de preservação e valorização desse patrimônio.

Neste contexto, a Educação Patrimonial é concebida como um método educativo que atua tanto no ensino formal quanto informal, sendo tomado, ainda, como um instrumento de "alfabetização cultural", no sentido elencado por Grunberg (2008, p. 39), qual seja:

\footnotetext{
[um instrumento] que permite ao cidadão fazer a leitura do mundo que o rodeia e compreender a sociedade e o momento histórico nos quais está inserido. [...] A habilidade de interpretar os objetos e fenômenos culturais amplia a capacidade de compreensão do mundo. Cada produto da criação humana, seja utilitário ou simbólico, é portador de significados e sentidos que devem ser lidos e decodificados através de sua forma, conteúdo e expressão.
}

No contexto dessa pesquisa, interagimos com a memória das comunidades locais ao trabalharmos com o patrimônio arqueológico nas suas vertentes paisagísticas, materiais, imateriais e legais. Adentramos, assim, em lugares de memória, como sítios arqueológicos e museus (NORA, 1993). Esse enfoque possibilita a ressignificação das referências espaciais de memórias locais, espaços de valorização histórica comum, onde a comunidade se reconhece ou reconhece o outro, por meio de imagens concretas ou apreensões visuais.

A preservação patrimonial está diretamente ligada ao sentimento cultural de pertencimento regional. Dessa forma, nosso projeto de Arqueologia vem trabalhando interdisciplinarmente com outras ciências como a História, Geografia e Biologia. Na Biologia os estudos estão relacionados com a evolução da paisagem e os aspectos ecológicos da planície costeira sul catarinense, a utilização dos recursos botânicos pelas populações atuais e pré-históricas para a alimentação, construção de moradias, artefatos, medicina e demais usos cotidianos. Na História relacionamos o Patrimônio Cultural com a possibilidade de dar visibilidade aos diversos grupos humanos que também fazem parte da história local e, que, hoje, constituem referências do passado no presente. Imbuindo, assim, nos Stakeholders locais, a ciência de que "as iniciativas educativas devem ser encaradas como um recurso fundamental para a valorização da diversidade cultural e para o fortalecimento da identidade local, fazendo uso de múltiplas estratégias e situações de aprendizagem construídas coletivamente" (IPHAN, 2014, p. 20). 
Assim, quando as crianças também se colocam como parte desse processo educativo, gerando um conhecimento sobre o seu lugar, estamos, por meio da educação patrimonial, possibilitando que ampliem e se aproximem da história da sua localidade por meio de diferentes perspectivas. Nesse sentido, "[...] a mediação pode ser entendida como um processo de desenvolvimento e de aprendizagem humana, como incorporação da cultura, como domínio de modos culturais de agir e pensar, de se relacionar com outros e consigo mesmo" (IPHAN, 2014, p. 22).

\section{ATIVIDADES REALIZADAS}

Na primeira etapa do projeto, desenvolvida nos meses de agosto e setembro de 2016, foram realizadas palestras com o corpo pedagógico da Escola Municipal José Réus. Foi feita uma reflexão sobre o conceito de Arqueologia e sua especialidade na materialidade humana, relacionando a produção da cultura material histórica e pré-histórica com a paisagem, inserida em um contexto de necessidades e práticas culturais.

Com os educadores foi realizado um workshop sobre o conceito de Patrimônio, Memória e Identidade, atrelando as práticas da educação ao patrimônio. Através das reflexões feitas acerca do assunto, foram relacionados os elos entre as temáticas patrimônio, memória e identidades (RODRIGUES, et al., 2017; CAMPOS, 2015; MATIAS, 2014).

Sendo assim, os educadores, relacionando com a prática da docência, intensificaram, na realização da extensão, a importância da manutenção das diversificadas memórias coletivas que compõem a identidade local. Essa prática ocorreu com a ativa participação da comunidade escolar para com seu patrimônio cultural, evocador dessas memórias. Tal percepção foi possível com a Educação Patrimonial e, portanto, a dialética pedagógica é fundamental nesse processo, possibilitando, assim, que os educadores reflitam sobre estratégias de atividades que compõem a temática no cotidiano escolar.

A última etapa dos trabalhos com o corpo docente foi realizada no Laboratório de Arqueologia Pedro Ignácio Schmitz (LAPIS/UNESC), onde os educadores puderam ter contato com as práticas laboratoriais que delineiam as pesquisas desenvolvidas no âmbito do projeto de arqueologia regional (Arqueologia entre Rios: do Urussanga ao Mampituba) e com o material arqueológico referente aos sítios da região, sobretudo à cultura material sambaqui (Figuras 1, 2 e 3). 


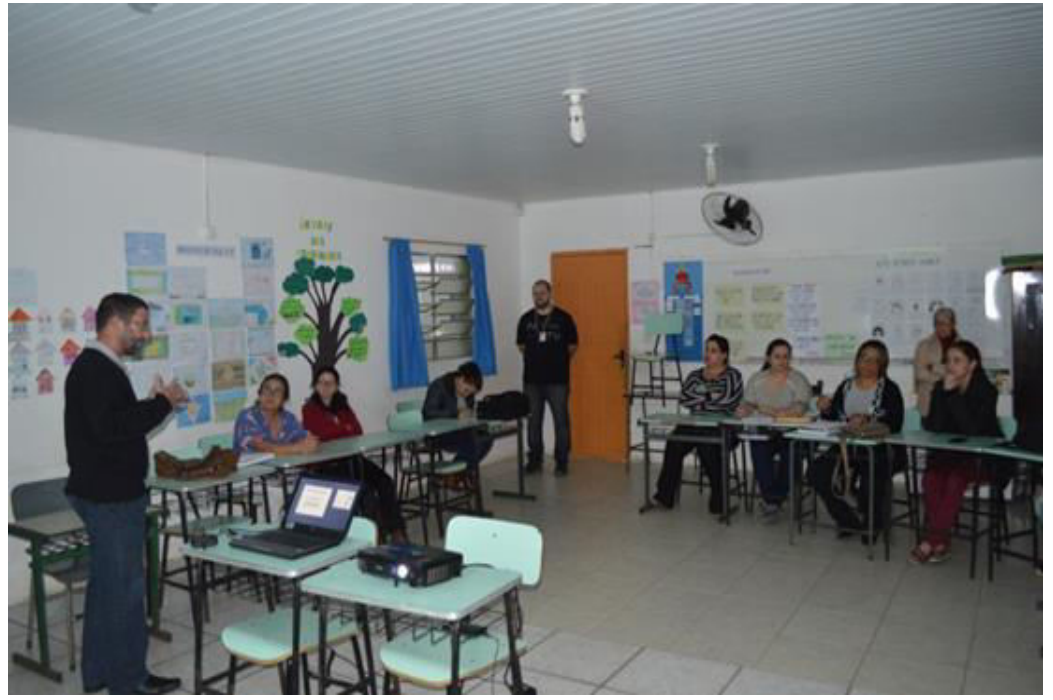

Figura 1 - Aulas expositivas sobre as características arqueológicas regionais. Fonte: os autores

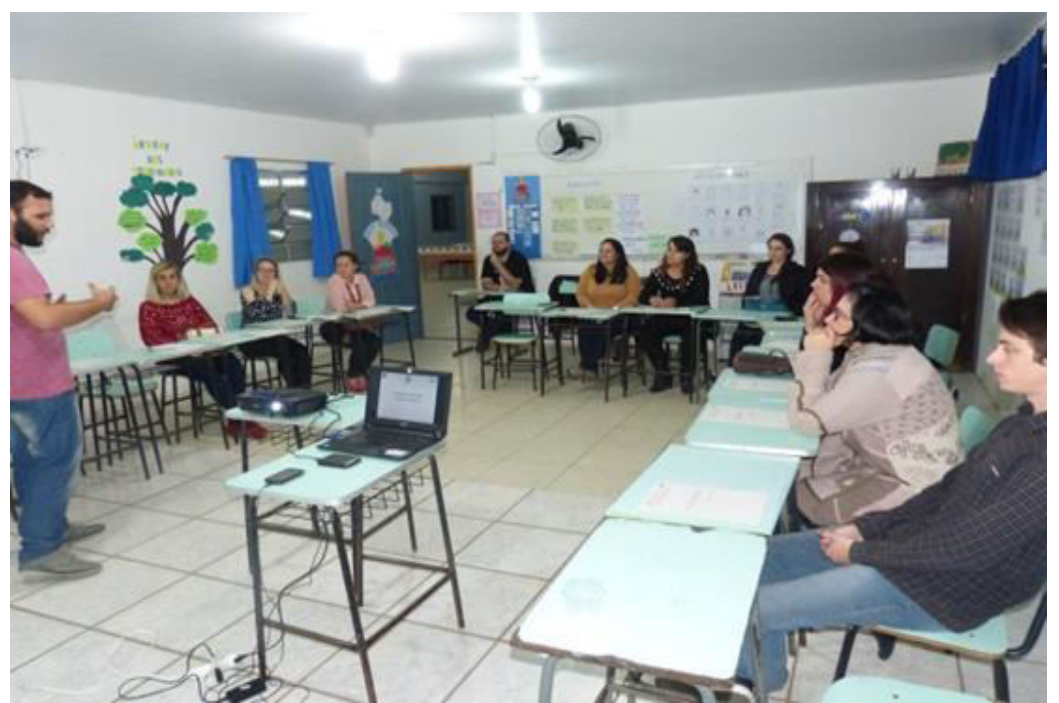

Figura 2 - Aulas expositivas sobre as características arqueológicas regionais. Fonte: os autores. 


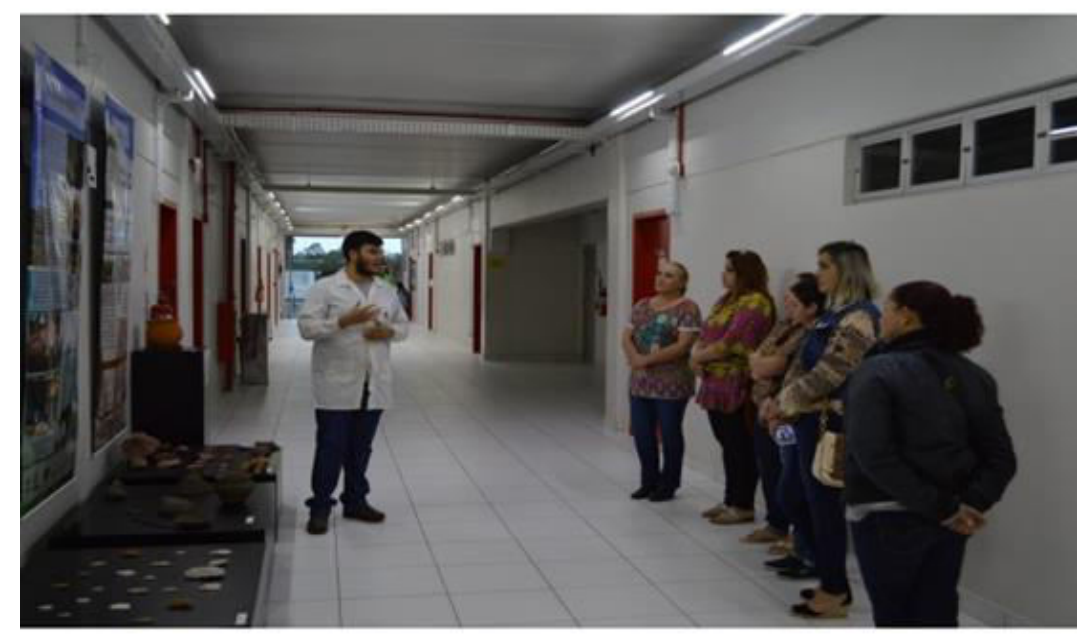

Figura 3 - Visita do corpo docente da escola EMEF José Réus às instalações do LAPIS.

Fonte: os autores.

No mês de maio de 2017, houve apresentações expositivas na escola José Réus para os alunos do $4^{\circ}$ e $5^{\circ}$ ano se familiarizarem com as culturas pré-históricas e históricas que habitavam a região e o trabalho do arqueólogo em campo. Posteriormente, os alunos tiveram experiências práticas e lúdicas por meio de oficinas (Tabela 1). Na sequência, os estudantes fizeram uma atividade avaliativa sobre os conhecimentos construídos.

\begin{tabular}{|c|l|}
\hline \multicolumn{2}{|c|}{ Atividades Práticas realizadas na escola EMEF José Réus situada no Balneário Rincão } \\
\hline Oficinas Temáticas & $\begin{array}{l}\text { Contato com a matéria-prima (argila) e e com a técnica } \\
\text { de confecção de vasilhames cerâmicos própria das } \\
\text { populações ceramistas que viveram no litoral sul } \\
\text { catarinense. }\end{array}$ \\
\hline Arte Rupestre & $\begin{array}{l}\text { Atividade que visou demonstrar aos alunos como as } \\
\text { populações antigas utilizavam os recursos existentes na } \\
\text { natureza para confeccionar instrumentos e pigmentos } \\
\text { para a realização de pinturas tanto em suportes } \\
\text { rochosos quanto em seus próprios corpos, ampliando as } \\
\text { percepções sobre essa dinâmica específica dentro do } \\
\text { âmbito cultural dessas populações. }\end{array}$ \\
\hline Vivência em escavação simulada & $\begin{array}{l}\text { Participação dos alunos em uma escavação } \\
\text { arqueológica simulada, na qual puderam ter contato, de } \\
\text { forma prática e lúdica, com noções e técnicas de parte } \\
\text { do cotidiano da pesquisa arqueológica em campo. }\end{array}$ \\
\hline
\end{tabular}

Tabela 1. Descrição das atividades ofertadas pelo projeto de pesquisa junto à escola EMEF José Réus.

Fonte: os autores. 
Dessa forma, os educandos puderam compreender o funcionamento de uma escavação arqueológica, como os povos pré-históricos se expressavam por meio de pinturas rupestres e como produziam os utensílios por meio da produção dos vasos cerâmicos (Figuras 4, 5 e 6).

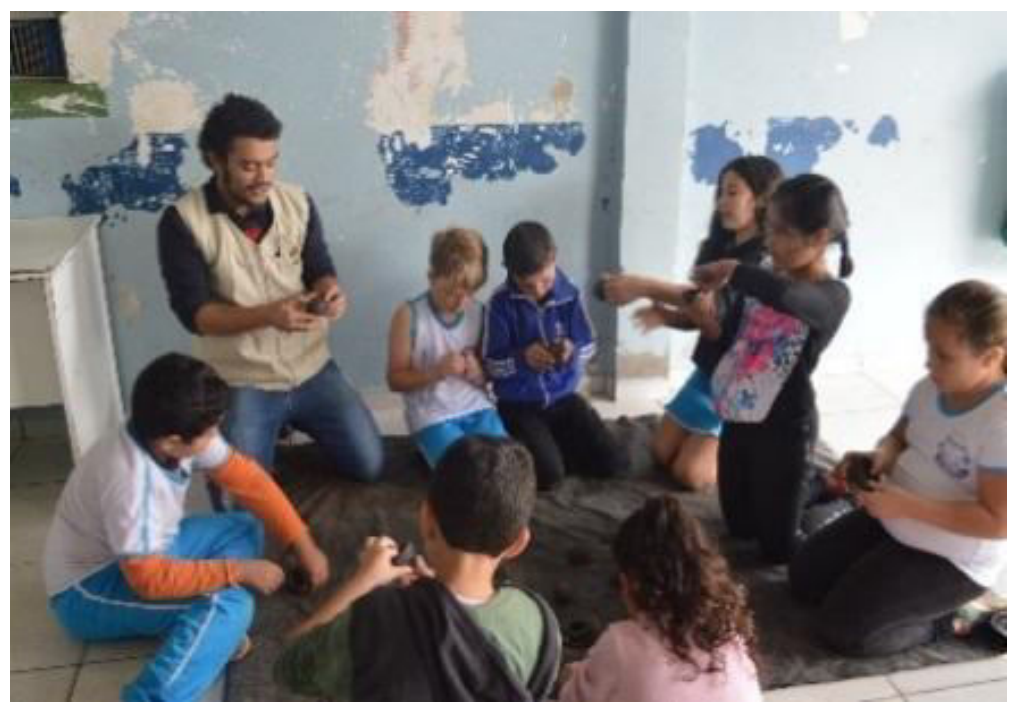

Figura 4. Educador demonstra as técnicas utilizadas pelos grupos humanos pré-históricos para a confecção de vasilhames cerâmicos.

Fonte: os autores.

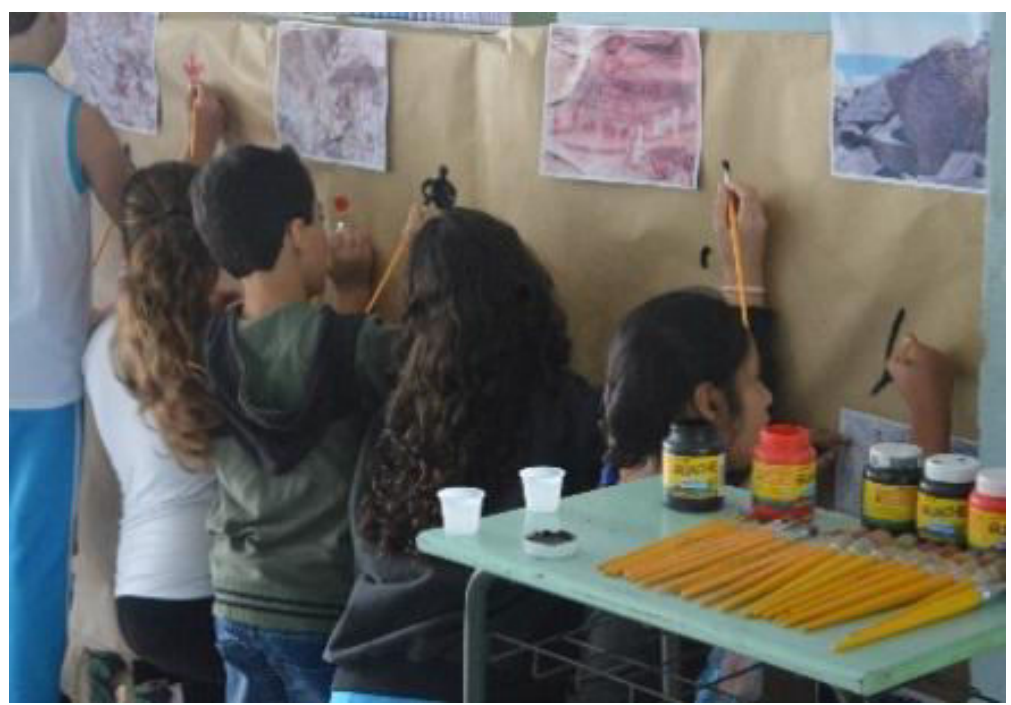

Figura 5. Alunos desenvolvem atividades ligadas à oficina de Arte Rupestre.

Fonte: os autores. 


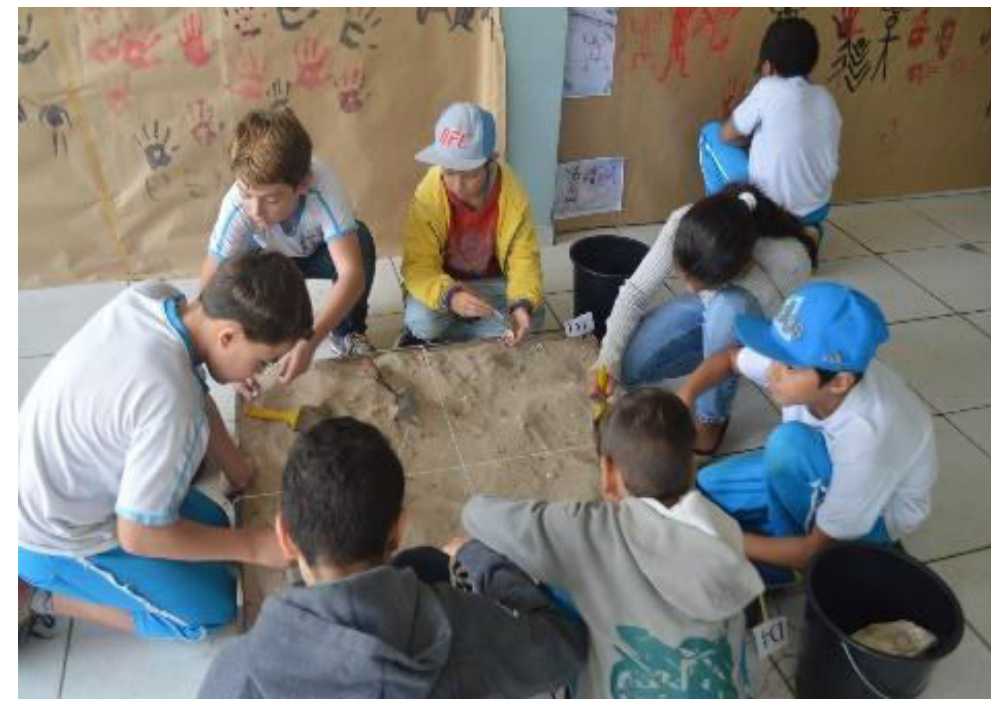

Figura 6. Alunos desenvolvem atividades ligadas à escavação arqueológica.

Fonte: os autores.

Utilizando a didática de forma lúdica, as oficinas foram realizadas com as turmas do $4^{\circ}$ e $5^{\circ}$ anos do Ensino Fundamental I. Nessas oficinas, os alunos foram divididos em três grupos para que todos pudessem participar de todas as atividades. Na oficina de escavação simulada, os alunos utilizaram as ferramentas do arqueólogo e puderam, através da prática, ter a noção de como é o desenvolvimento do trabalho exercido em campo. Na oficina de cerâmica, os educandos tiveram como base alguns vasos cerâmicos para a confecção de seus próprios recipientes e, utilizando argila como matéria prima, puderam aprender as técnicas de roletado e maldura e acabamento alisado e corrugado. Na oficina de pintura rupestre, os alunos foram apresentados a algumas imagens préhistóricas que serviram como base para sua pintura, realizada com pincel e tinta. 


\section{CONSIDERAÇÕES FINAIS}

Ao propiciar à comunidade escolar, em especial aos alunos, vivências com a Educação Patrimonial, demonstramos o nosso compromisso com uma prática educativa que compreende e acolhe a diversidade de histórias, memórias e identidades como ponto de partida para a preservação do patrimônio local. E, nesse sentido, a importância de se conhecer a história do patrimônio ou do objeto encontrado em sua comunidade, além dos benefícios científicos tem-se também a inserção social do indivíduo, já que "valorizando no ser humano os aspectos intelectuais, morais e estéticos, procura despertar sua consciência individual harmonizada ao grupo social ao qual pertence" (FERRAZ; FUSARI, 1999, p. 150).

Os trabalhos desenvolvidos em parceria com a EMEF José Réus seguiram de acordo com os planejamentos do projeto. Percebemos a empolgação dos alunos pelo assunto por meio das atividades lúdicas. Durante essas atividades, eles puderam vivenciar a diversidade da cultura material dos povos históricos e pré-históricos que antes habitavam a região e, com isso, reforçou-se a importância da preservação dos sítios arqueológicos e a visualização destes como um patrimônio cultural que precisa ser reconhecido e preservado pela comunidade.

Os conhecimentos construídos pelos alunos sobre os temas abordados nas oficinas possibilitaram, na prática, a conexão dos conhecimentos aprendidos na oficina de escavação e sua posterior atividade de análise em laboratório. Os alunos vivenciaram de uma forma lúdica aspectos da Arte Rupestre, tendo contato com as diferentes representações, pintadas e gravadas, da Préhistória brasileira. Na confecção dos vasos cerâmicos, desenvolveram conhecimentos técnicos para reconhecer e confeccionar seus próprios vasos, aprendendo como os povos históricos produziam seus utensílios.

As apresentações alcançaram os resultados esperados, isto é, possibilitaram que os alunos do Ensino Fundamental I da Escola Municipal José Réus percebessem a existência do patrimônio arqueológico, bem como suas características na paisagem regional, entendendo sua importância e valor cultural. Os alunos foram imbuídos de conhecimentos arqueológicos que encontram paralelos com a atualidade, interligando as culturas indígenas com a história local da comunidade. Por fim, percebemos que a Educação Patrimonial como atividade de extensão é uma mais valia para a problematização, valorização e preservação da cultura arqueológica. 


\section{AGRADECIMENTOS}

Agradecemos a diversos colegas que contribuíram de diferentes maneiras: Giovana Pereira, Giovana V. Cadorin, Josiel dos Santos, Jodoel Cardoso, Alexandre Sachet, Diego Moser, Elisangela da Silva Machieski. Mencionamos, ainda, o apoio institucional da Universidade do Extremo Sul Catarinense (UNESC), EMEF José Réus, Museu de Arqueologia e Secretaria de Educação do município de Balneário Rincão de Santa Catarina. A responsabilidade pelas ideias restringe-se aos autores.

\section{REFERÊNCIAS BIBLIOGRÁFICAS}

BARON, Dan. Alfabetização Cultural: a luta íntima por uma nova humanidade. São Paulo: Alfarrábio, 2004.

CAMPOS, Juliano Bitencourt.; SANTOS, Marcos César Pereira; ROSA, Rafael Casagrande da; RICKEN, Claudio; ZOCCHE, Jairo José. Arqueologia Entre Rios: do Urussanga ao Mampituba. Registros arqueológicos pré-históricos no extremo sul catarinense. Cadernos do LEPAARQ, v. 10, n. 20, p. 9-40, 2013a.

CAMPOS, Juliano Bitencourt; MARQUES, Birgts Harter; ZOCCHE, Jairo José. Do Urussanga ao Mampituba: registros arqueológicos no extremo sul catarinense e a gestão integrada do territórios. In: LADWING, Nilzo Ivo; SCHWALM, Hugo. Gestão socioambiental das cidades no século XXI: teorias, conflitos e desafios. Florianópolis: Insular, 2013b, p. 229-266.

CAMPOS, Juliano Bitencourt. Arqueologia Entre Rios e a Gestão Integrada do Território no Extremo Sul de Santa Catarina - Brasil. Vila Real, Universidade de Trás-os-Montes e Alto Douro, p. 261, 2015. (Tese de Doutorado em Quaternário, Materiais e Cultura) Universidade de Trás-os-Montes e Alto Douro, Vila Real, Portugal, 2015.

CEZARO, Herom Souza; SANTOS, Marcos Cesar Pereira; CAMPOS, Juliano Bitencourt. Interpretação De Sítios com Arte Pré-Histórica: o Caso do Sítio Malacara I e Toca do Tatu. Revista Memorare, Tubarão, SC, v. 3, n. 1, p. 47-72, 2016.

FERRAZ, Maria Heloísa Corrêa de Toledo; FUSARI, Maria Felisminda de Rezende e. Metodologia do Ensino de Arte. São Paulo: Cortez, 1999.

GRUNBERG, Evelina. Educação Patrimonial: trajetórias. In: BARRETO, Éuder Arrais et al. Patrimônio Cultural e Educação: artigos e resultados. Goiânia: UFG, 2008, p. 37-41.

IPHAN. Educação patrimonial: histórico, conceitos e processos. IPHAN, 2014. Disponível em: <http://portal.iphan.gov.br/uploads/ckfinder/arquivos/Educacao Patrimonial.pdf>. 
MATIAS, Carlos dos Passos Paulo; ZOCCHE, Jairo José; SANTOS, Marcos Cesar Pereira; SANTOS, Josiel dos; RONCONI, Richard Vieira; CAMPOS, Juliano Bitencourt. Socialização do Conhecimento: Reflexões Educacionais sobre o Patrimônio Histórico do Extremo Sul Catarinense. In: CAMPOS, Juliano Bitencourt; ZOCCHE, Jairo José; CEREZER, Jedson Francisco; OOSTERBEEK, Luiz Miguel. (Org.). Arqueologia Iberoamericana e Transatlântica: Arqueologia, Sociedade e Território. Erechim: Habilis Press, 2014, p. 377388.

NORA, Pierre. Entre memória e história: a problemática dos lugares. Projeto História. Revista do Programa de Estudos Pós-Graduados de História. v. 10, 1993.

RODRIGUES, Marram Helen da Silva Gomes; CAMPOS, Juliano Bitencourt; FARIAS, Deisi Scunderlick Eloy; DEBLASIS, Paulo; SANTOS, Marcos Cesar Pereira; ZOCCHE, Jairo José. Gestão Integrada do Patrimônio e da Paisagem Cultural: Breves Considerações. In: Nilzo Ivo Ladwig; Hugo Schwalm. (Org.). Planejamento e gestão territorial: gestão integrada do território. 1ed. Criciúma: Editora Unesc, 2017, v. 1, p. 310-321.

SANTOS, Marcos Cesar Pereira; COSTA, Juliano Gordo; CAMPOS, Juliano Bitencourt. Escolhas De Matérias-Primas Rochosas Por Grupos Pré-Históricos Caçadores-Coletores Na Microbacia Do Rio Da Pedra. Jacinto Machado/Santa Catarina. Cadernos do LEPAARQ (UFPEL), v. 12, n. 23, p. 22-42, 2015.

SANTOS, Marcos Cesar Pereira; PAVEI, Diego Dias; CAMPOS, Juliano Bitencourt. Arqueologia Entre Rios: do Urussanga ao Mampituba: paleoambiente, cultura material e ocupação humana na paisagem litorânea do Extremo Sul Catarinense entre 3500-200 anos antes do Presente. Cadernos do CEOM, v. 29, n. 45, p. 64-86, 2016.

SANTOS, Marcos Cesar Pereira; PAVEI, Diego Dias; CAMPOS, Juliano Bitencourt. Sambaqui Lagoa dos Freitas, Santa Catarina: estratigrafia, antiguidade, arqueofauna, e cultura material. Revista Memorare, v. 5, n. 1, p. 157-196, 2018. 